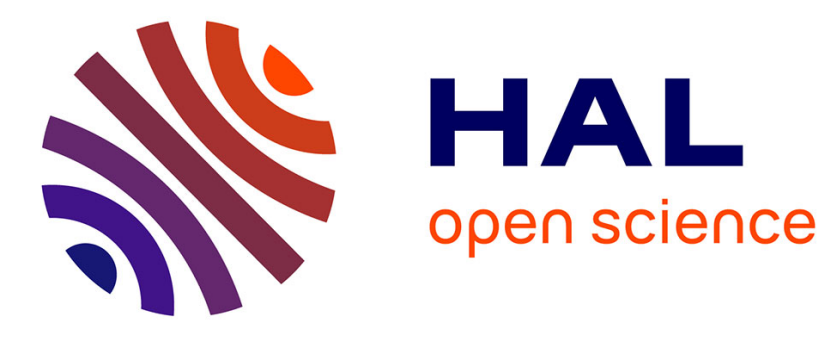

\title{
Modelling and Image Processing of Constriction and Proliferation in the Gastrulation Process of Drosophila melanogaster
}

Muhammad Tayyab, Athanasios Lontos, Emmanuel Promayon, Jacques Demongeot

\section{To cite this version:}

Muhammad Tayyab, Athanasios Lontos, Emmanuel Promayon, Jacques Demongeot. Modelling and Image Processing of Constriction and Proliferation in the Gastrulation Process of Drosophila melanogaster. Proc. IEEE Workshops of Int Advanced Information Networking and Applications (WAINA) Conf 2011, 2011, France. pp.473-477, 10.1109/WAINA.2011.152 . hal-00613193

\section{HAL Id: hal-00613193 https://hal.science/hal-00613193}

Submitted on 3 Aug 2011

HAL is a multi-disciplinary open access archive for the deposit and dissemination of scientific research documents, whether they are published or not. The documents may come from teaching and research institutions in France or abroad, or from public or private research centers.
L'archive ouverte pluridisciplinaire HAL, est destinée au dépôt et à la diffusion de documents scientifiques de niveau recherche, publiés ou non, émanant des établissements d'enseignement et de recherche français ou étrangers, des laboratoires publics ou privés. 


\title{
Modelling and image processing of constriction and proliferation in the gastrulation process of Drosophila melanogaster
}

\author{
M. Tayyab ${ }^{1,2}$, A. Lontos ${ }^{2}$, E. Promayon ${ }^{2}$, J. Demongeot ${ }^{1,2 *}$
}

\begin{abstract}
The initial stage of gastrulation, an early stage of embryogenesis, is called invagination, or primitive streak formation. In the first part of the paper, we analyse by using image processing techniques the cell deformation and motion in he Drosophila melanogaster embryo searching to delimit the first period of invagination without proliferation. Then, in a second part, we propose a biomechanical model, based only on the consideration of elastic and contractile forces exerted on cell walls and on the centrosome through the combination of myosin contraction and cytoskeleton rigidity. Numerical simulations of this model made during the period of gastrulation without proliferation suggest that the model adequately simulates in-vivo cell behaviour, showing the start of the streak formation at the two extremities of the embryo cylinder, followed by a propagation of the invagination to its central part.
\end{abstract}

Keywords: cell contouring, cell counting, gastrulation, biomechanical model, streak formation, invagination simulation

The living organisms are very complex - part digital and part analogy mechanisms. J. von Neumann [1].

\section{INTRODUCTION}

During the morphogenesis of the gastrula, the second step of the embryogenesis after the blastula stage, we observe in the majority of the animal development dynamics, the following phenomena: i) the cell motion is partly guided by chemotaxis, in order to supply their substrate demand, and also to respect the epigenetic architecture ruled by morphogens, ii) the cell shape is due to a constriction controlled by cell differentiation and iii) the final gastric tube is obtained from cell proliferation relaxing the forces exerted on the cell plasmic membrane and optimizing the cellular "nutritive Area / inner Volume" (A/V) ratio. Concerning the differentiation process, some cells of the embryo start to take the shape of a bottle (bottle or flask cells), decreasing the surface at the interface with their nourishment fluid. At the end of the gastrulation, these bottle cells start to divide and grow, increasing their $\mathrm{A} / \mathrm{V}$ ratio. In this paper, we are attempting firstly to follow by using image processing techniques the first phase of the gastrulation made of pure cell

Manuscript received 15th November 2010.

${ }^{1}$ Laboratory AGIM, FRE CNRS University J. Fourier of Grenoble, Faculty of Medicine, 38700 La Tronche, France

${ }^{2}$ Laboratory TIMC-IMAG, UMR 5525 CNRS University J. Fourier of Grenoble, Faculty of Medicine, 38700 La Tronche, France

*corresponding author: Jacques.Demongeot@imag.fr,

e-mails: tayyab.elite@gmail.com, Athanasios.Lontos@imag.fr,

Emmanuel.Promayon@imag.fr motion causing the invagination without any proliferation, and secondly to show that the cell constriction results in a streak starting on the two extremities of the embryo and propagating secondly to its central part. In order to simulate the initiation of this phenomenon, we use exclusively laws of physics and mechanics. For this purpose, we have created a threedimensional biomechanical model consisting of a group of cells, forming a structure with two areas: a cylindrical rigid area representing the main embryo body and two curved hemispheric areas constituting the embryo extremities. Each cell is modelled by a set of Newtonian contour particles defining the surface mesh and an inner particle, located at the geometric centre of the cell, mimicking the centrosome. Elastic forces are used to model the rigidifying effect of the tubulin and actin cytoskeleton, and contractile forces to model the action of the myosin fibers. In addition, we have modelled the role of the cadherins by connecting contour particles of adjacent cells. Finally, in order to ensure the symmetry from a partial mesh representing only a part of the embryo, we have applied boundary conditions to the particles located at the lateral extremity edges of the simulated structure. This biomechanical model shows that the inner folding starts at the curved area and then propagates to the rigid one, in accordance with the in vivo process. To compare these results with in vivo experiments, we have monitored the displacement of the centrosome and the cell $\mathrm{A} / \mathrm{V}$ ratio. Our numerical experiments made during the time lag observed through the microscopic imaging without proliferation suggest that our model adequately simulates thge in-vivo cell behaviour. In a first part, we present image processing techniques and results obtained by applying them on gastrulation microscopic recording of Drosophila melanogaster embryo from [2-6]. In a second part, we describe the biomechanical model of streak formation and the third Section will be devoted to the presentation of numerical simulations confronted to real images of the first invagination stage of the gastrulation.

\section{IMAGE PROCESSING}

2.1. Image processing techniques: cell countouring and counting

Many cell-based research studies require the counting of cells prior to beginning an experiment. Estimation of cell density in various regions of embryo is thus an integral part of such studies. Profile counts or stereological techniques could be used to have an estimate of the cell density in a particular region. The regions where cell density increases enormously 
care, if they occur, our regions of interest. Image enhancement techniques need to be applied on the images to get welldefined cell contours. The available images depict actinmyosin networks in colour. Here, we are focussing more on cell boundaries in a particular region, in order to have an idea of cell density; and to observe cells whether they divide in those regions. After evaluating the colour histogram of the image, we filter out the noise by selecting an appropriate colour threshold value. In absence of noise, cell boundaries are easily visualized and hence cells could be tracked. Cell boundaries are further enhanced by applying contrast algorithms on the colour-filtered image again by using simple threshold values after studying the gray-histogram. Cell proliferation results in increase in volume, thereby causing cells to recurrently contract then stabilize. Older cells are more vulnerable to shrink themselves as a result of forces from the neighbouring cells, due to proliferation at the other end. Cell density, as expected, would increase enormously in such regions with respect to other regions (Figure 1), pushing them due to proliferation. Cell density increasing enormously in such regions with respect to other regions which could lead to invagination, close to the point of maximum cell density.

\subsection{Results obtained from cell contouring and counting}

Available series of images were processed to have an idea of change of cell density in the region where a constriction appeared at a later stage. After following the image processing steps explained in 2.1., we were able to have an exact visual idea of how the cells move and how changes the cell density in the region where invagination occurs experimentally, and also to observe if there is any division of cell in that region before the development of constriction. This included removal of noise from the images and then applying contrast and contour algorithms, to have an exact visual idea of the number of cells in that region. All cells could be individually tracked, and change of their forms are clearly observed. However, no division of cells was observed in the region where in the later stage, constriction appeared. Instead, cells get squeezed and cell density increased in that particular region before we could see two points in-line, across which this phenomenon occurred, leading finally to the development of a constriction.

\section{THE BIOMECHANICAL MODEL}

\subsection{The embryo architecture}

The embryo cylindric cephalo-caudal structure (Figure 2) has two zones of cylindricity breaking, the two hemispheric extremities and the cells at the boundary between the two geometries presents a curvature due to a relaxation of the internal rigid properties of their cytoskeleton. Tha appearnce of the gastrulation streak occurs at their level and after propagates to the central cylindric part of the embryo. Taking into account the differential contractility of these boundary cells constitutes the model core and will be implemented over a 3D mesh representing the external embryo surface.
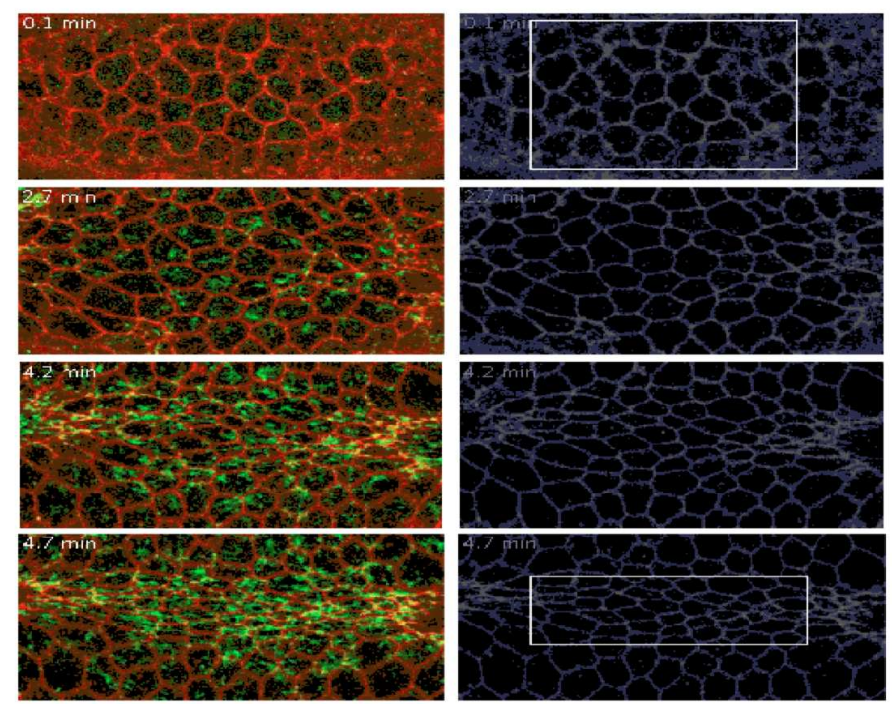

Figure1. Invagination process between initial and final stage from available data, $[2-6]$ just before invagination, rectangle showing area of interest
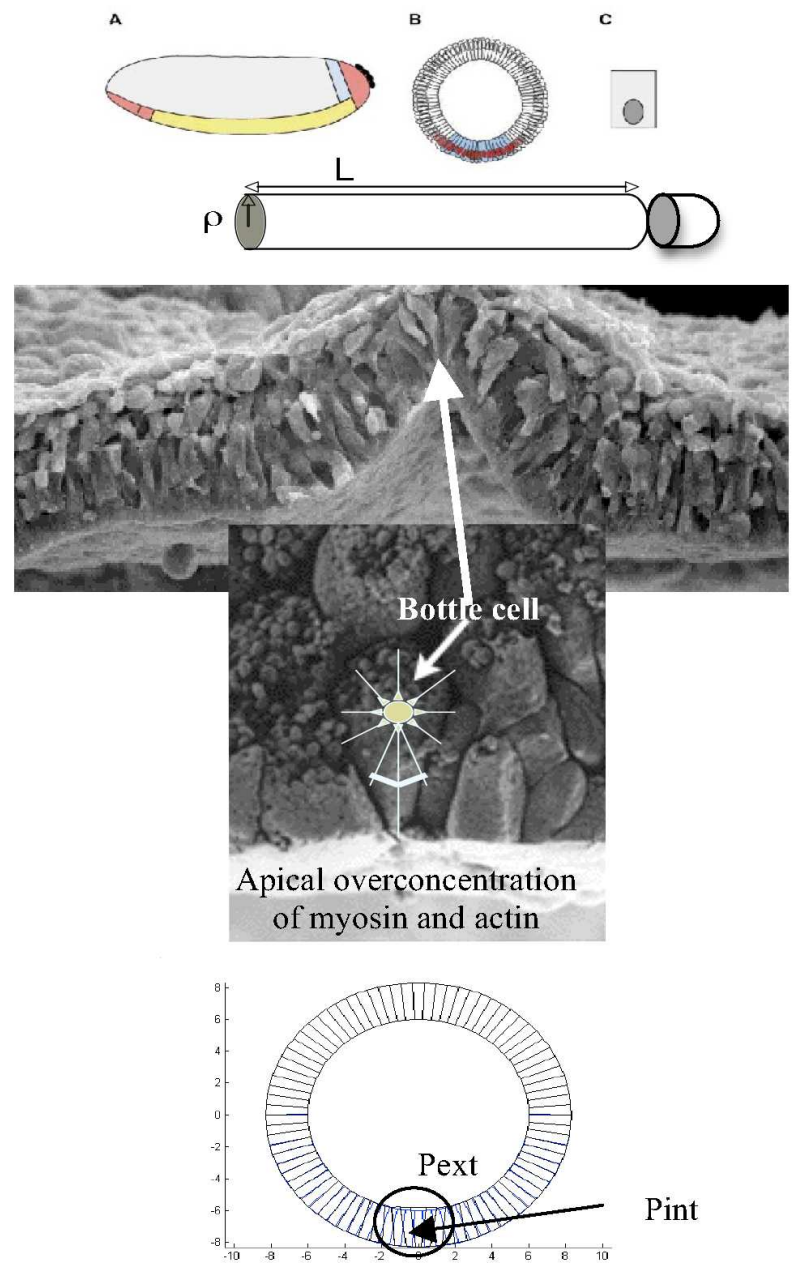

Figure 2. Top: Cylindric structure of Drosophila melanogaster embryo of length $\mathrm{L}$ and hemispheric left extremityies. Middle: differentiation of the first bottle (or flask) cell. Bottom: equilibrium between external and internal forces 


\subsection{The model}

Each cell evolves following the mechanical laws:

1) the sum of the orthogonal forces exerted on the cell walls is equal to its mass (proportional to its inner area) times its orthogonal (to the wall) acceleration. The external forces are the resultant of the extracellular (Pext) and intracellular (Pint) pressure, the contact forces being exerted by the neighbouring cells (sharing a part or the whole of the wall) exerted by other cells and the internal force is due to the cell pressure exerted via the cyto-skeleton and the plasmic membrane [7]. Each force is equal to a coefficient (e.g. the physical pressure) times the length of the wall on which it is exerted

2) If we suppose that the initial cell configuration is in an equilibrium state, we calculate an admissible set of parameters values respecting this equilibrium

3) Then, we leave the cell system evolve depending on the energetic balance ruling the cytoskeleton apical polymerization [4-6] controlled by a specific genetic regulatory network comprizing essentially concertina (cta), actin, myosin, Rho and RhoGEF genes [7-10], by choosing a small time step, by updating sequentially each cell and by calculating their displacements respecting the no-overlapping rule. At each step we update the cell common walls by supposing that cell contacts are close, ensured between cells by cadherins and gap junctions [11,12], and with the extracellular matrix by integrins and adhesins. Cell motion involves a change in its inner area: we suppose that growth occurs where internal forces Fint are larger than external ones Fext (cell has to be stretched), as for constrained growth in continuous media mechanics. When the external forces dominate, the cell is supposed compressible and can be constricted. The cells divide longitudinally or laterally when their ratio perimeter over area is too small [13-17].
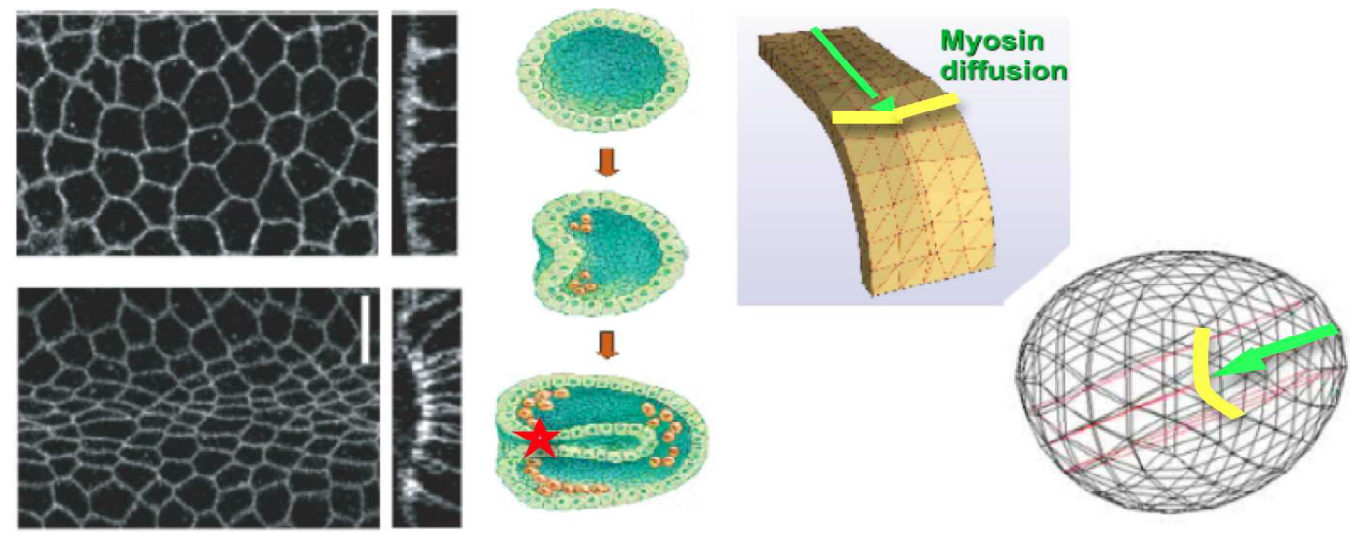

Figure 3: Left: cell contraction due to myosin (experiments [36]). Centre: progressive invagination and streak formation. Right: myosin diffusion along a directrix of the cylindric part of the embryo (green arrow) provoking the invagination before the tube closure (red star). The zero-diffusion domain for myosin is indicated in yellow.

The revolution symmetry breaking consists in making two cylinders inside the embryo cylinder, one coming from the ventral furrow and giving the digestive tube (this phase is called gastrulation) and the other coming from the dorsal furrow and giving the neural tube (this phase is called

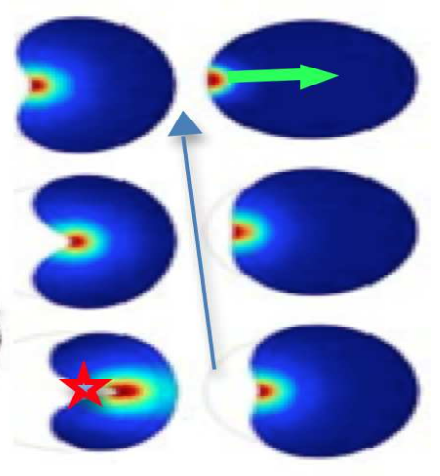

neurulation). The first gastrulation step consist in an apical concentration overfluctuation of one of the cytoskeleton components (myosin, actin, tubulin,...) or one of the enzymes (ADenylate Kinase - ADK - or Nucleoside Diphosphate Kinase - NDK) or one of the energy molecules (ATP, GTP) involved [18-23]. This apical overconcentration diffuses and reaches the extremities [11,12] of the cylindric portion of the embryo at which gap junctions are less important with the cells of the "hemispheric" terminations. Then two first bottle cells can appear at the two extremities of the diffusion line, then this first contraction can propagate until the center of the cylindric part as noticed in $[11,12]$ during the 6 first hours of the gastrulation in Drosophila melanogaster. After this first phase of the ventral furrow formation, for regularizing the tensegrity forces, based on a synergy between balanced tension and compression components of cells, first divisions occur from extremities to center by applying the first Thom's cell law. We can simulate such a process on a transversal slice of the embryo and reproduce the invagination of the gastrulation from both the contraction and consecutively the proliferation phases.

The end of the cell and tissue growth stops correspond to the the second Thom's tissue law is applicable (the surface to volume ratio of an organ becoming adverse) or when the organ is completely covered by an anatomic boundary like an aponeurosis made of fibrous cells or an autoassemblage of extracellular ingredients.

In both these cases, a couple of morphogens acting often simultaneously in opposite (e.g. a couple of activator and inhibitor like BMP-7 and BMP-2 in feather morphogenesis in the chicken $124-27\rceil$ can induce the chemotactic motion of

fibroblats or the biosynthesis of the elements constituting the auto-assemblage (like proteins and phospholipids). The fact that for a certain value of their viscosity ratio, the morphogens can coexist for a relatively long time in a precise location can greatly favor the birth of anatomic organ boundaries.

\section{NUMERICAL SIMULATIONS}

The myosin is supposed to diffuse in all directions from a cell in which an excess of myosin is synthesized caused by random fluctuations over-expressing its gene, notably along a directrix end of the morphogenesis process: this can be observed when 
of the cylinder constituting the body of the embryo of Drosophila melanogaster. This directrix represents the shortest path until the hemispheric extremities of the embryo on the boundary of which cells change of curvature (yellow on Figure 3). The whole model mixes a Multi-Agents Model (MAM) responsible for cell growth, migration and proliferation with a Reaction-Diffusion Partial Differential Equation (RD-PDE) for myosin dispatching, mainly in charge of cell contraction.

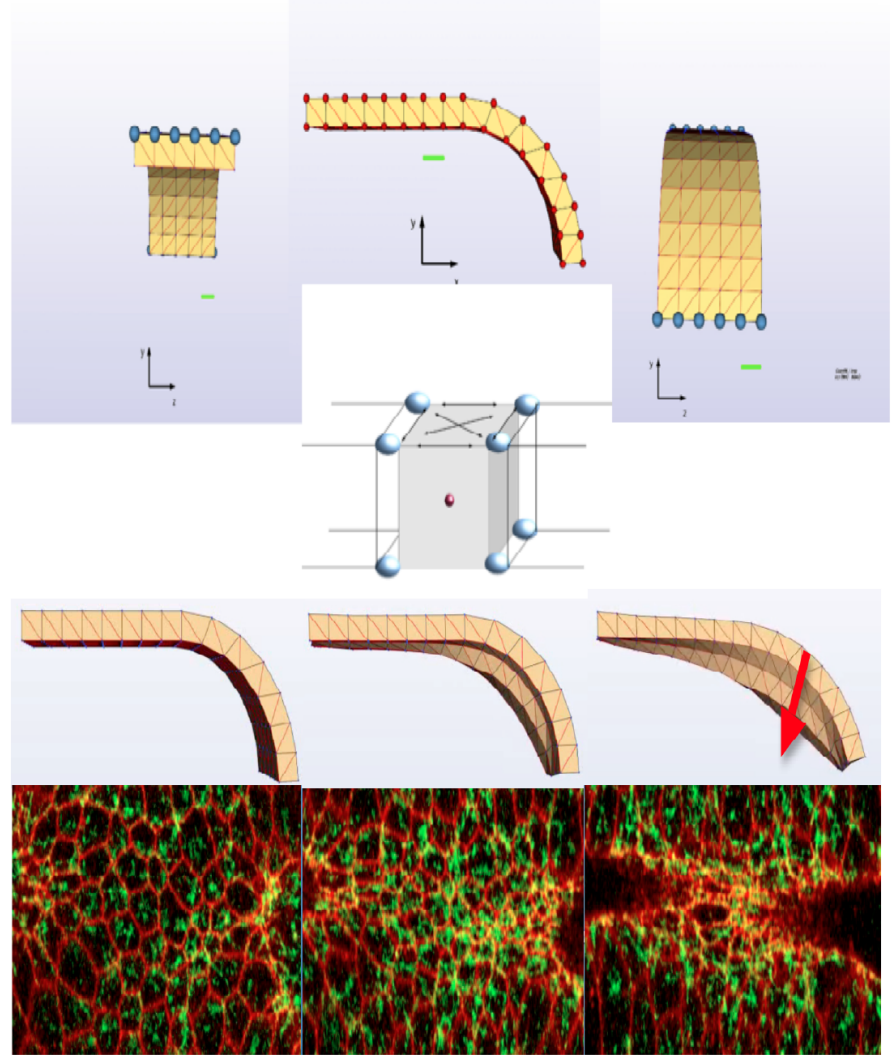

Figure 4: Top: part of the embryo made of cells considered as polyhedra with 8 vertices common with neighbouring cells and a center (the centrosome) related to the vertices by actin filaments and micro-tubules (constituting the elastic and rigid cytoskeleton) on which myosin using ATP exerts contraction forces. Dark blue points are fixed points of the whole structure. Middle: profile of the structure under the contractile action of the myosin showing the start of the streak at the boundary of the hemispheric extremity of the embryo (red arrow). Bottom: experimental observation of the activity of myosin (fluorescent) with distal invagination

The results of simulation of the hybrid model are given on Figures 3 and 4 showing the same phenomena as those observed in experiments: the progressive invagination starts at the extremities of the embryo and after propagates to the central cylindric part of the embryo. The final step of the gastrulation needs proliferation in order to close the internal of the cell differentiation in bottle (or flask) cells contracted at their apical extremity, provoking during the first minutes of gastrulation a reorganization of the superficial cell layer of the embryo without division, leading to the formation of a streak. Resulting invagination starts experimentally at the 2 extremities of the embryo and propagates to its central part.cylinder which will give birth to the intestinal tube of the adult animal. By following the progressive migration in embryo depth of the centrosomes it appears that the run is faster and deeper for curved cells at the extremities of the embryo than for central cells (Figure 5). The saturation curves representing this displacement behave like the curves representing the evolution of the cell diameter under progressively increasing forces applied externally to the cell, which is a way to induce cell contractions (possibly periodic [30]) similar to those due to myosin (Figure 6) [31, 32]. Some divisions of the observed bottle (or flask) cells whose differentiation is due to myosin gene over-expression, suffice to end the gastrulation process if they occur at critical locations as streak lips (red star on Figure 3), located at the boundary of the zero-diffusion domain both observed and simulated for myosin (in yellow on Figure 3).

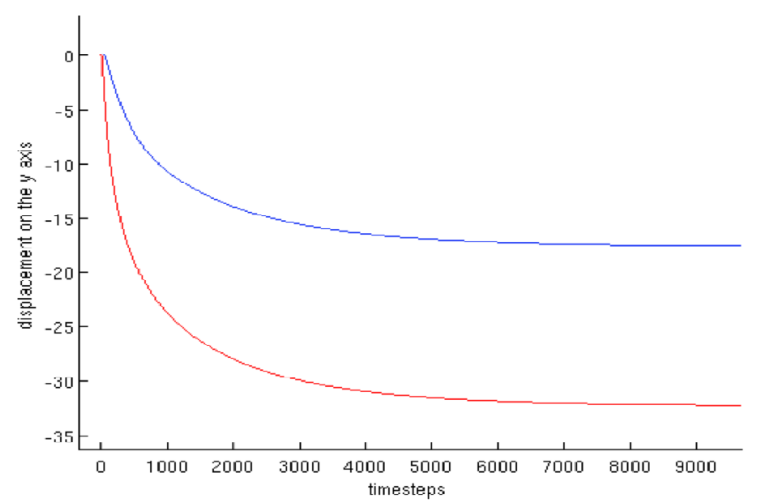

Figure 5: Displacement of centre particle (virtual centrosome) of a cell located on the cylindrical part of the embryo (blue), substantially smaller and slower than displacement of centrosome of cell located at the curved area (red).

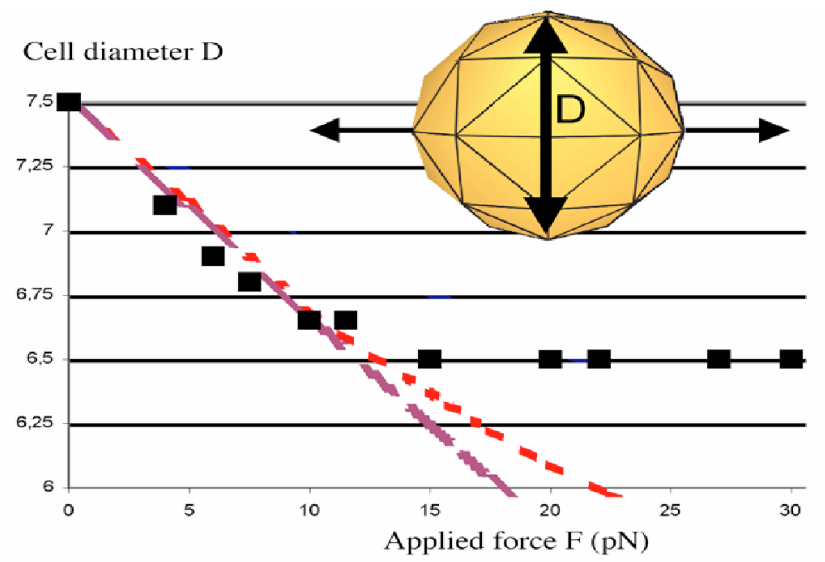

Figure 6: Simulated virtual spherical red blood cell (RBC) suspended in an hypotonic solution. Optical tweezers double trap is simulated by exerting locally a force $F s$ on two opposite nodes of the cell object contour (upper insert). The variation with load of the cell object diameter $\mathrm{D}(\mathrm{F})$ (in $\mu \mathrm{m}$ ) in a plane perpendicular to the loading direction is simulated and compared to experimental data published by [31] (black squares). With appropriate scaling of the force, it is possible to adjust the elasticity modulus such that experimental mechanical response of RBC is nicely fitted in the linear elastic regime (red). Increasing the elasticity modulus induces a stiffer response which qualitatively reproduces the departure from the linear regime at larger traction forces (violet) 


\section{CONCLUSION}

We given in this paper some examples (centred around the gastrulation process) concerning different steps of morphogenesis modelling from experimental acquisition of pertinent data until the interpretation in a mathematical framework of the dynamic or the geometric features of observed forms and functions.

We will in the future increase the spatial and temporal resolution of the data by sampling in $3 \mathrm{D}$ with a good precision in space (e.g. by using confocal or biphotonic microscopic information), in time (e.g. by using the cine-microscopy) and in function (e.g. by using the Raman vibrational, infrared,..., spectro-microscopy), in order to detect precisely the frontiers between the successive phases of the morphogenetic process of revolution symmetry breaking in the embryo, i.e., i) the morphogen diffusion, ii) the cell migration, iii) the bottle cell differentiation, iv) the streak contraction and $v$ ) cell the proliferation ensuring vi) the tube closure.

\section{REFERENCES}

[1] J. von Neumann, "The general and logical theory of automata," Collected Works V, Pergamon Press, Oxford, pp. 288-326, 1951.

[2] http:www.ibioseminars.org

[3] http:www.molbio1.princeton. edu/wieschaus/

[4] A.C. Martin, M. Kaschube, E. Wieschaus, "Pulsed contractions of an actin-myosin network drive apical constriction," Nature, Vol. 457, pp. 495-499, 2009

[5] A.M. Sokac, E. Wieschaus, "Zygotically controlled F-actin establishes cortical compartments to stabilize furrows during Drosophila cellularization," J Cell Sci., Vol. 121, pp. 1815-1824, 2008.

[6] A.M. Sokac, E. Wieschaus, "Local actin-dependent endocytosis is zygotically controlled to initiate Drosophila cellularization, " Dev Cell., Vol. 14, pp. 775-786, 2008.

[7] M. Leptin, "Gastrulation in Drosophila: the logic and the cellular mechanisms," The EMBO Journal, Vol.18, pp.3187-3192, 1999.

[8] J. Demongeot, J. Aracena, F. Thuderoz, T.P. Baum, O. Cohen, "Genetic regulation networks: circuits, regulons and attractors," Comptes Rendus Biologies, Vol. 326, pp. 171-188, 2003.

[9] J. Aracena, M. González, A. Zuñiga, M. Méndez, V. Cambiazo, "Regulatory network for cell shape changes during Drosophila ventral furrow formation," J. Theor. Biol., Vol. 239, pp. 49-62, 2006.

[10] F. Caraguel, M. Tayyab, F. Giroud \& J. Demongeot, "Evolution of the genetic regulatory networks: the example of the cell cycle control network. From gastrulation modelling to apocatagenesis," in: IEEE AINA' $10 \& B L S M C^{\prime}$ 10, IEEE Press, Piscataway, pp. 767-774, 2010.

[11] H. Oda, S. Tsukita, "Real-time imaging of cell-cell adherens junctions reveals that Drosophila mesoderm invagination begins with two phases of apical constriction of cells," Journal of Cell Science, Vol. 114, pp. 493-501, 2000.

[12] R.E. Dawes-Hoang, K.M. Parmar, A.E. Christiansen, C.B. Phelps, A.H. Brand, E.F.Wieschaus, "Folded gastrulation, cell shape change and the control of myosin localization," Development, Vol. 132, pp. 4165-4178, 2006.

[13] R. Thom, "Stabilité structurelle et Morphogenèse," Benjamin, New York, 1972.

[14] L. Forest, J. Demongeot, "Cellular modelling of secondary radial growth in conifer trees: application to Pinus radiata," Bull. Math. Biol., Vol. 68, pp. 753-784, 2006.

[15] L. Forest, S. Martinez, F. Padilla, J. Demongeot, J. San Martin, "Modelling of auxin transport affected by gravity and differential radial growth," J. Theor. Biol., Vol. 241, pp. 241-251, 2006.
[16] L. Forest, J. San Martin, F. Padilla, F. Chassat, F. Giroud, J. Demongeot, "Morphogenetic processes: application to cambial growth dynamics. Acta Biotheoretica," Vol. 52, pp. 415-438, 2004.

[17] L. Forest, J. Demongeot, "A general formalism for tissue morphogenesis based on cellular dynamics and control system interactions," Acta Biotheoretica, Vol. 56, pp. 51-74, 2008.

[18] N. Glade, J. Demongeot, J. Tabony, "Numerical Simulations of microtubule self-organisation by reaction and diffusion," Acta Biotheoretica, Vol. 50, pp. 232-248, 2002.

[19] J. Tabony, N. Glade, J. Demongeot, C. Papaseit, "Biological selforganisation by way of microtubule reaction-diffusion processes," Langmuir, Vol. 18, pp. 7196-7207, 2002.

[20] J. Tabony, N. Glade, C. Papaseit, J. Demongeot, "Microtubule selforganisation as an example of the development of order in living systems," J. Biol. Phys. Chem., Vol. 4, pp. 50-63, 2004.

[21] N. Glade, J. Demongeot, J. Tabony, " $\mu$ tubule self-organisation by reaction-diffusion processes causes collective transport and organisation of cellular particles," BMC Cell Biol., Vol. 5:23, 2004.

[22] N. Glade, J. Demongeot, J. Tabony, "Numerical Simulations of microtubule self-organisation by reaction and diffusion," Acta Biotheoretica, Vol. 50, pp. 232-248, 2002.

[23] J. Tabony, N. Glade, J. Demongeot, C. Papaseit, "Biological selforganisation by way of microtubule reaction-diffusion processes," Langmuir, Vol. 18, pp. 7196-7207, 2002.

[24] L. Abbas, J. Demongeot, N. Glade, "Synchrony in Reaction-diffusion models of morphogenesis: applications to curvature-dependent proliferation and zero-diffusion front waves, Phil. Trans. Royal Soc. A, Vol. 367, pp. 4829-4862, 2009.

[25] F. Michon, L. Forest, E. Collomb, J. Demongeot, D. Dhouailly, "BMP-2 and BMP-7 play antagonistic roles in feather induction," Development, Vol. 135, pp. 2797-2805, 2008.

[26] L. Forest, F. Michon, S. Cadau, J. Demongeot, D. Dhouailly, "What is the biological basis of pattern formation of skin lesions? Viewpoint 4. Skin Patterns belong to three main types, determined at three steps of development," Exp. Dermatology, Vol. 12, pp. 559-564, 2006.

[27] J. Demongeot, "Biological boundaries and biological age," Acta Biotheoretica, Vol. 57, pp. 397-419, 2009.

[28] B. Baum, N. Perrimon, "Spatial control of the actin cytoskeleton in Drosophila epithelial cells," Nat. Cell Biol., Vol. 3, pp. 883-890, 2001.

[29] J. Gates, J.P. Mahaffey, S.L. Rogers, M. Emerson, E.M. Rogers, S.L. Sottile, D. Van Vactor, F.B. Gertler, M. Peifer, "Enabled plays key roles in embryonic epithelial morphogenesis in Drosophila," Development, Vol. 134, pp. 2027-2039, 2007.

[30] A.C. Martin, M. Kaschube, E.F. Wieschaus, "Pulsed contractions of an actin-myosin network drive apical constriction," Nature, Vol. 457, pp. 495-499, 2009.

[31] S. Hénon, G. Lenormand, A. Richert, and F. Gallet, "A new determination of the shear modulus of the human erythrocyte membrane using optical tweezers," Biophys J., Vol. 76, pp. 1145-51, 1999.

[32] P. Tracqui, E. Promayon, P. Amar, N. Huc, V. Norris, and J.L. Martiel, "Emergent features of cell structural dynamics: a review of models based on tensegrity and nonlinear oscillations," in: Modelling and simulation of biological processes in the context of genomics, P. Amar, F. Képès, V. Norris and P. Tracqui (eds.), Genopole, Evry, 2003, pp. 160-189. 